\title{
Application of technological innovations in marketing activities of the enterprise
}

\author{
Darkhan Onaltayev ${ }^{1}$, Aigerim Kazhmuratova ${ }^{1}$, Sandygul Akhmetkaliyeva ${ }^{1}$, Rilla \\ Malikova $^{1}$, Aliya Yelyubayeva ${ }^{1 *}$ \\ ${ }^{1}$ Al-Farabi Kazakh National University,050040,71 Al-Farabi Ave, Almaty, Kazakhstan
}

\begin{abstract}
This article presents the results of the study of problems related to the management of business activity of high-tech companies, the key components of which are include innovation and marketing activities. These components of entrepreneurial activity are interrelated, because as innovation activity increases, so does the need for increased marketing activity to ensure that the market is ready to consume new products. In turn, it creates conditions for a wide release of innovations and rapid return on investment. It is proposed to evaluate and regulate innovation and marketing activities are carried out using a combination of provided indicators and models. For successful management of innovation and marketing activities relevant mechanisms are required. The article describes their methodological features. Three types of strategic orientations are also considered: customer, technology and combined customer / technology orientation. We analyze their direct impact on the effectiveness of innovation, as well as the deterrent effect of marketing management in terms of the marketing mix about these relationships.
\end{abstract}

\section{Introduction}

Transfer of the Kazakhstan economy to the innovative way of development requires revolutionary changes in the management of scientific and production complexes in order to increase the competitiveness of national innovations in the world markets in the context of economic globalization. In these conditions, the creation of mechanisms related to the management of innovation and marketing activities of micro- and nanoelectronics increased [1]. Consistency of these types of activity is conditioned by the fact that when innovations occur, the market must be ready to consume new products. In real practice, one can observe the lack of readiness of consumers to use the novelty. It restrains the growth of production volumes of new products and the decrease in its cost price. Innovation and marketing

Corresponding author: ertis economika@mail.ru 
activities become a key component of entrepreneurial activity [2].

Every year the company performs its functions simultaneously with its current activity and develops. Business activity reflects the aggregate results of the intensity of current activity and strategic development. Economic proportions should be completed between these types of activities, because imbalances (observed in real practice) lead to financial instability and imbalance of activity. Business activity is an integrated result of the impact of such activities as production, innovation, marketing, financial (investment), labor, economic, intellectual and social activities [3].

In order to build a high-quality interconnection infrastructure, it is also necessary to synchronize financial, human resources and material flows in space and time. An industry cluster has proven itself to be a good organizational form of interconnection, which corresponds to all the above conditions and market positions of highly efficient technologically advanced products. It is recognized in the process of economic globalization [4].

Market instability has a significant impact on the results of entrepreneurial activity, carried out by business entities, and above all, on the management of marketing intensity of the company. As for the marketing systems based on market relations, the term "intensity" requires a deeper purposeful focus on "confrontation" with the external or internal system, which must be overcome. The strength of this confrontation changes depending on its members, their energy and goals. In this case, "marketing intensity" is interpreted as an opportunity for development and confrontation with the forces of market economy, and, above all, competitiveness. There are different forms of confrontation of market forces, but the nature of their emergence is the same. Methods related to the change of marketing activity and its intensity depending on many factors (the environment of the system, the internal structure and nature of the interrelationships of elements, potential opportunities) and the negative phenomena that seek to disturb its integrity and harmony. agrees with the resource-oriented view of the firm, the new knowledge is also an important resource that can provide firms with a sustainable competitive advantage if such resources are valuable for clients, then surpass those and

Problems related to changes in production trends, i.e. the reasons for their change and the mechanisms associated with the transfer of systems from one state to another are directly related to the problems of economic cyclicality of development. A generalized structural-logic scheme analyzing the innovation process, which includes the stages of functioning of systems and features of these systems, which change each other and cause different goals, problems and conditions and conditions for their solution. They include:

- The needs of the population

- Organization of the innovation process,

- Research and development, experimental and technological works,

- Production

- Operation

- Use [5].

Different forms of interconnection between systems and their components increase the complexity of evaluation and selection of the best strategy to maintain or enhance marketing activity, especially since market situations are often unpredictable. The problems of marketing activities and innovative development become especially important in the conditions of the network interaction of systems, the current market economy. The question arises about the necessity and possibility of creating a mechanism for coordination or coordination of economic activities of agents in order to obtain maximum use from each of them (or their connection) in order to ensure the integrity and efficiency of economic and technical systems during their interaction [6]. Different forms of interrelation between the systems and their components increase the complexity of assessment and selection of the 
best strategy for maintaining or strengthening marketing activity, especially as market conditions are often unpredictable. The problems of marketing activity and innovative development become especially important in the conditions of the network of systems interaction, the economy taking place in the modern market. The question arises about the necessity and possibility of creating a mechanism for coordination or coordination of economic activities of agents in order to obtain maximum use from each of them (or their connection) in order to ensure the integrity and efficiency of economic and technical systems during their interaction [6].

Such a conservative model existed everywhere by the end of the 20th century. XX century. However, the development of science and technology has led to an increase in the cost of technological development, provided that the cost of innovative products decreases simultaneously and the opportunity to benefit from investment in innovative products. From the point of view of the marketer, the long-term component of product novelty has decreased. At the same time, access to knowledge about new technologies and new markets has become increasingly difficult. Consequently, R\&D costs have decreased, and fundamental research has been replaced by applied research. This led to the emergence of the concept of new innovations (NI) [7]. The innovation process is an integral part of scientific and technological progress. It is organically built into the mechanism of development of commodity-money relations. Such components of this mechanism as competitiveness, producer, consumer and state in the constantly changing contradictory interdependence. The implementation of the process related to the renewal of knowledgeintensive technologies is particularly complex. When developing the mechanism of innovation activity management, the following main methodological provisions are taken into account: Innovative development is characterized by periodic changes in models, series and generations of equipment, devices, and technology. This leads to the renewal of the product line. Objects of innovation differ in terms of the timing of the innovation cycle, the level of complexity of the development of objects and the level of readiness for their perception by both the manufacturer and the consumer [7].

At present, the developed countries of the world are experiencing a real technological boom, when all new innovative developments in various fields of activity change previous approaches. Whereas previously the most important factor in the development of the country's economy was the availability of mineral resources (oil, gas, ore, etc.), now creative individuals and teams capable of creating breakthrough innovations have come to the fore. Until recently, many innovations seemed to be fantastic, but they have already entered the market firmly into everyday life of people in different countries of the world. These are electric cars and electric scooters, 3D printers, various gadgets with more and more advanced functions, internet trading, blockchain technology and the latest medical products. We can insure ourselves against excessive risks of mineral depletion by using the example of the Bashkir soda company based in Sterlitamak. Today, the company is facing a shortage of minerals for its mining operations. The problem is so serious that the company's management is going to make massive cuts and even shut down its production. To ensure the sustainable development of the company, it is proposed to create an additional subdivision, which will be focused on high-tech electrical products. First, you need to understand the idea of the project. In our case, it would be extremely interesting to establish a very popular today production of electric cars. Today, there is a boom in electric cars in the USA, Canada, Norway, China and the EU. The leader is the successful project of I. Mask, which became a successful transnational corporation Tesla. There is a study of the successful production of electric cars and electric buses in Shenzhen with the support of the state. Another possible project is the launch of a production line for $3 \mathrm{~d}$-component printers, which allow the printing of cheap homes and offices.

The most significant (in terms of the impact on the innovation process) production 
parameters include the target production volume (production capacity) and the size of the enterprise, i.e. significant characteristics. The more these values are, the more inertial the production system is, and as a consequence, the slower the implementation of renewal processes. The analysis of practice connected with updating of production and manufacture proves necessity to consider the factor of assortment of production when to introduce technological innovations because there is a causal factor connection between them. At the same time, the causal model of the radical and evolutionary types of technological innovations are different [8].

Table 1.Innovative efficiency and marketing management related to marketing activities in combination with the orientation of the firm.

\begin{tabular}{|c|c|c|c|c|c|}
\hline $\begin{array}{c}\text { Company } \\
\text { orientation }\end{array}$ & $\begin{array}{c}\text { Client } \\
\text { orientation } \\
\text { (COA) }\end{array}$ & $\begin{array}{c}\text { Technological } \\
\text { Orientation Alone } \\
\text { (TOA) }\end{array}$ & $\begin{array}{c}\text { Combined } \\
\text { orientation }\end{array}$ & $\begin{array}{c}\text { no identifiable } \\
\text { orientation }\end{array}$ & whole sample \\
\hline $\begin{array}{c}\text { Total number of } \\
\text { companies }\end{array}$ & 359 & 192 & 505 & 547 & 1603 \\
\hline $\begin{array}{c}\text { Not innovators } \\
(\%)\end{array}$ & $138(39 \%)$ & $102(53 \%)$ & $293(58 \%)$ & $395(24 \%)$ & $667(42 \%)$ \\
\hline $\begin{array}{c}\text { Innovation } \\
\text { activities }\end{array}$ & 0.06 & 0.07 & 0.11 & 0.04 & 0.07 \\
\hline $\begin{array}{c}\text { Marketing } \\
\text { management }\end{array}$ & 1.16 & 1.05 & 1.15 & 0.92 & 1.08 \\
\hline
\end{tabular}

In such studies, the breadth includes sources of customer knowledge, as well as sources related to technological knowledge from other firms, public and private laboratories and universities. According to this study, we expect that firms with a combined orientation will be more successful in implementing innovations than other types of firms. More intelligence due to the combined customer/technology orientation means that these firms can access additional types of knowledge that can be recombined to produce successful innovations [8]. These arguments suggest the following hypothesis: Combined "client/technology orientation" is more positively related to innovation activities than any of them. Client-centric' alone or with orientation technologies.

Table 2 presents the indicators characterizing the share of organizations engaged in certain types of marketing innovations in the total number of American organizations that had ready-made marketing innovations in 2014-2018. As we can see, a significant part of the innovation is the change in packaging. This is a less expensive way of innovation.

Table 3 shows that the main part of the innovation is in the technological part, but it is decreasing rapidly, and more emphasis is placed on the introduction of marketing tools. With the help of this management of innovation activity becomes one of the main reasons for the success of modern innovations. Marketing innovations can be a separate product, be a technology of innovative marketing, as well as a consequence of other types of innovations. 
Table 2. Dynamics of the share of organizations that carry out certain types of marketing innovations in the total number of American organizations that had ready-made marketing innovations in the period of 20014-2018.

\begin{tabular}{|c|c|c|c|c|c|}
\hline \multirow{2}{*}{ Type of marketing innovation } & \multicolumn{5}{|c|}{ Share of organizations, $\%$} \\
\hline & 2014 & 2015 & 2016 & 2017 & 2018 \\
\hline $\begin{array}{c}\text { Introduction of significant } \\
\text { changes in the design of goods and } \\
\text { services }\end{array}$ & 61,6 & 65,9 & 62,9 & 68,3 & 76 \\
\hline $\begin{array}{l}\text { Introduction significant changes } \\
\text { to the packaging }\end{array}$ & 81,3 & 76,3 & 71,2 & 75,8 & 77,7 \\
\hline $\begin{array}{l}\text { Use of new promotion } \\
\text { techniques }\end{array}$ & 62,6 & 63 & 61,8 & 62,4 & 64 \\
\hline $\begin{array}{l}\text { Implementation of the new } \\
\text { marketing strategy }\end{array}$ & 70 & 65,9 & 62,8 & 62,9 & 66,7 \\
\hline Use of new sales channels & 40,9 & 35,5 & 36,1 & 42,5 & 42,3 \\
\hline $\begin{array}{l}\text { Introduction of a new product } \\
\text { presentation concept }\end{array}$ & 41,9 & 41,2 & 35,1 & 42,5 & 44 \\
\hline Use of new pricing strategies & 48,8 & 50,7 & 48,2 & 52,2 & 53,7 \\
\hline Other marketing innovations & 3,9 & 3,8 & 4,2 & 8,6 & 4 \\
\hline
\end{tabular}

Table 3.Share of enterprises and organizations engaged in technological, organizational and marketing innovations (2015-2018), \%.

\begin{tabular}{|c|c|c|c|c|}
\hline \multirow{2}{*}{ Types of innovation } & \multicolumn{4}{|c|}{ Share of organizations, \% } \\
\cline { 2 - 5 } & 2015 & 2016 & 2017 & 2018 \\
\hline $\begin{array}{c}\text { Technological } \\
\text { innovations }\end{array}$ & 41,2 & 42,8 & 37 & 26,5 \\
\hline $\begin{array}{c}\text { Organizational } \\
\text { innovations }\end{array}$ & 10,7 & 11,1 & 10,6 & 11,2 \\
\hline Marketing innovations & 23,6 & 17,1 & 16,8 & 17,2 \\
\hline
\end{tabular}

\section{Literature review}

According to Belz, in order to ensure consistent development, each operation of the production system (production line, workshop, plant) must be changed regularly or continuously. The development of the system involves changes related to the updating of the technological base and the technical base of the production, the changing organizational 
structure of management, starting the production of completely new products. The final results of the development of production systems are expressed in improving the quality of functioning of the enterprise and ensuring its competitiveness[9].

Implementation of the process related to the renewal of knowledge-intensive products, which is the basis for a particular complexity is innovative development. This is due to the fact that the production of high quality and high-tech high-tech products does not require so much an increase in the costs of the innovation process (however, it is objectively necessary) as the improvement of the organizational mechanism for the implementation of these processes, - said Lessmann[10].

From the point of view of Zeadally, the main functions of the enterprise, to include the function of renewal of the output products, products of innovation are determining (or primary) and interrelated with other types of innovation. As a rule, the creation of completely (or radically) new products directly determines the need to introduce appropriate innovation processes of production, labor resources and organizational and management activities [11].

While scientific and technical progress is accelerating, it increases the requirements for business decisions to be made and implemented under severe restrictions, which mainly determine the zone of marketing activities of the company, - said Butt[12].

In this transition period, the role of marketing is unique and twofold: at the micro level it is a tool for placing an enterprise in the formed market environment and a means of attracting investment, and at the macro level it is an instrument of market environment, said Arslan[13].

According to Granell, the imposition of the influence of internal and external environment factors has contributed to the emergence of risk situations that cause unbearable losses. It is known that in order to reduce market risks, various tools can be used, including modern marketing technology (behavior in a competitive environment, the formation of commodity price policy, the distribution and promotion of policy products, etc.) [14].

The need for development arises in case of conflict between the current system and the growing needs of consumers of products, as well as the terms and conditions of competitiveness in the market, - said Bhoyar[15] .

According to Suppatvech, previous studies have studied the mitigating effects of both factors on the external and internal relations between strategic orientation and organizational efficiency. External factors include market turbulence, intensity of competition and technological changes[16].

We rely on resource theory to suggest that firms require organizational capabilities to use the knowledge resources they control in order to achieve a central understanding of the target markets," said Enkel[17].

When organizing innovation processes, it is necessary to be aware of the level of radicality (or complexity) of innovation. The introduction of any innovation causes contradictions between the specific changes made to the system and the system's desire for stability and integrity. Innovative will break the balance of the system for a certain period of time. This is one of the reasons for the negative treatment of innovations in production and organizational systems. In this regard, when implementing innovation processes, it is necessary to have a mechanism of compensation. This allows us to reduce the effect of innovation on the stability and balance of production system," said Clarke [18].

The most important part of the innovation process is the search for new knowledge that can be used to develop commercially successful products. Research in the field of evolutionary economics shows that new knowledge allows not only to promote new ideas on established trajectories, but also to create new combinations of knowledge and generate new trajectories," said Nelson [19]. 
According to Ziyadin, innovative technological solutions are relevant, bringing new and growing achievements in the organization. Among the goals, there are works in which their achievements play a major role in the firm. With their help, vital goals are achieved. This can be isolated in the expansion of work opportunities for new business discoveries or simply sustainability to meet current business needs.

We rely on resource theory to suggest that firms require organizational capabilities to use the knowledge resources they control in order to achieve a core understanding of the target markets, Barney said [21]. Opportunities that can be associated with innovation efficiency in terms of commercialization of new products include those related to marketing management, says Danneels.

Appiah-Adu suggests that combined customer/technology orientation should be more closely linked to innovation activities than either orientation alone. This provision is consistent with previous studies and shows that organizations that focus on both product/innovation and the market are both successful.

\section{Methodology}

1. Innovation process is an integral part of scientific and technological progress. It is organically built into the mechanism of development of commodity-money relations. Such components of this mechanism as competitiveness, producer, consumer and state in the constantly changing contradictory interdependence. The implementation of the process associated with the renewal of knowledge-intensive technologies products are particularly difficult. When developing the mechanism of innovation activity management the activities of high-tech companies, the following main methodological provisions are taken into account:

2. Innovative development is characterized by periodic changes in models, series and generations of equipment, devices, and technology. This leads to the renewal of the product line. Objects of innovation differ in terms of the timing of the innovation cycle, the level of complexity of the development of objects and the level of readiness for their perception by both the manufacturer and the consumer.

3. In the conditions of high dynamics and uncertainty of the external environment environment and growth of innovative activity of companies, etc. it is necessary to form a special mechanism related to the management of the innovation cycle of new products creation. To make decisions when planning the level of innovation, the types of activities to be considered in the list of methodological features. The following methodology is proposed to form an economic model for assessing the level of innovation activity [25].

4. The key indicators characterizing innovation activity are the selected ones. Key indicators should be decisive, independent and relevant. Such indicators may include:Коэффициент обновления продукции, т. е. доля новых продуктов (qn ) в общем перечне выпускаемой продукции (1),.

$$
\mathbf{K} u p d=\mathbf{q} \mathbf{n} \div \mathbf{I}
$$

Progressive coefficient of the technologies used (production, information, organizational and management);

5. The coefficient of intensity of assimilation of new products is characterized by the ratio of the number of types of assimilated products (n) to the annual period in months $(\mathrm{K}=$ $\mathrm{n} / 12$ ). This indicator is used in the case of comparative analysis of the analysis of high-tech companies and the actual planning of renewal rates. For example, the average renewal rate in one company is $\mathrm{K}=2$ products / month, while in another company it is $\mathrm{K}=0.5$ products / month. 
This coefficient characterizes the level of innovation potential and readiness of the company to develop[2].

\section{Results}

Investment expenses as a percentage of total sales. This share reaches $7-11 \%$ for a hightech company. The index of relevant changes is determined for each key indicator. This ratio of the target period to the base period (previous report). For example, the baseline value for the previous period was Kupd $=0.15$ (or $15 \%$ of new products in the total list of products produced), and the target for the reporting period will be 0.2 . In this case, the update period will be

$$
\text { I } u p d=\mathbf{0 . 2} \div \mathbf{0 . 1 5}=\mathbf{1 . 3 3}
$$

which characterizes the growth of product renewal by $33 \%$.

Production renewal, as well as any transition process, is characterized by

1. Accidental production

2. Dynamic changes in his condition

3. Instability of technological parameters of production during the period of assimilation

4. Increased production costs

5. Socio-psychological discomfort of the personnel in the development of new products.

6. Support the use of ICT SMEs and consumers, including remote areas, by providing easy and low-cost access to ICT solutions.

7. Organization of regular consultative meetings and exchange of knowledge with other areas in order to identify appropriate ICT strategies and implementation plans and timetables.

\section{Conclusion}

The strong interrelation of innovative and marketing problems in modern business systems is imposed the need for their joint consideration. The variety of tools and methodological methods of development allow to select them according to the specific conditions depending on the complexity of the problems arising. Systemic consideration of business activity as a response to the disturbing impact of the business environment allows to expand the possibilities of adaptation of modern high technology production and marketing organizations to changes. In the process of research we have formed the conditions and determined the limitations necessary for the development of the mechanism of management of innovative and marketing activities in the development of high-tech companies. For the purpose of formation of the concept of management of innovative activity development of the hi-tech company on the basis of regulation of innovative and marketing potential, it is necessary to specify further events and to specify methodical materials in a context of changes [3]. introduction of the additional division on manufacture of innovative hi-tech production at the enterprise the enterprise based on digital economy, is an important basis for steady growth strategy of the traditional enterprise. Later on, the assortment of high-tech products is expanded, and the assortment of outdated, unclaimed products is reduced. Due to online sales, the company will expand its sales market and enter foreign markets. This strategy will provide the former traditional enterprise, far from innovation, with maximum competitiveness in the fight against the giants-Apple, Alphabet, Tesla, Amazon, etc. 


\section{References}

1. S. Ray, Int. J. Prod. Econ. 95(3), 327-345 (2005)

2. A. Jabbar, P. Akhtar, S. Dani, Ind. Mark.Manag. (2019)

3. P. Adams, I. M. B. Freitas, R. Fontana, J. Bus. Res. 97, 129-140.(2019)

4. G. Guido, M. Pichierri, R. Nataraajan, G. Pino, J. Bus. Res. 69(12), 60486057.(2016)

5. S., Li, J. Li, et al. J. Exp. Syst. Applic. 38(8), 10606-10613.(2011)

6. P. S. Leeflang, P. C. Verhoef et al. Europ. Manag. J. 32(1), 1-12.(2014)

7. J. Järvinen, H. Karjaluoto, Ind. Market. Manag. 50, 117-127. (2015)

8. A. M. Schüller, G. Fuchs, U. M. V. M. Kleinsorgen, Gabler,17-32(2007)

9. C. Belz, M. Schögel, T. Tomczak,). Gabler, 3-20 (2007)

10. S. Lessmann, J. Haupt et al. Inform. Sci.(2019)

11. S., Zeadally, , A. K., Das\& N Sklavos,. Cryptographic technologies and protocol standards for Internet of Things. Internet of Things, 100075. (2019)

12. S. S. Arslan, R. Jurdak et al. Advancements in Distributed Ledger Technology for Internet of Things(2019)

13. C. Granell, D. Havlik et al. Envir. Model. Soft., 78, 1-15. (2016).

14. P. Bhoyar, P. Sahare, S. B. Dhok, R. B. Deshmukh, AEU-Int. J. Electr. Com. (2018)

15. C. Suppatvech, J. Godsell, S. Day, Ind. Market. Manag. (2019)

16. E. Enkel, O. Gassmann, H. Chesbrough, R\&d Manag. 39(4), 311-316.(2009)

17. G. R. Clarke, C. Z. Qiang, L. C. Xu, The Internet as a general-purpose technology: Firm-level evidence from around the world. The World Bank (2015)

18. R. R. Nelson, An evolutionary theory of economic change(2009)

19. S. Ziyadin, S. Suieubayeva, A. Utegenova, Springer, Cham,408-415 (2019)

20. E. Danneels, Strat. Manag. J. 28(5), 511-533 (2007)

21. A.V. Bataev, A.A. Gorovoy, A.B. Mottaeva, Proceedings of the 32nd International Business Information Management Association Conference, 102-114 (2018) 